\title{
Retraction Note: Analysis of mountain rock structure and athlete's jogging action based on Internet of Things
}

\author{
Zhiqiang Zeng ${ }^{1} \cdot$ Dandan Wang $^{2}$
}

Published online: 6 December 2021

C) Saudi Society for Geosciences 2021

Retraction Note: Arabian Journal of Geosciences (2021) 14: 1415 https://doi.org/10.1007/s12517-021-07759-z

The Editor-in-Chief and the Publisher have retracted this article because the content of this article is nonsensical. The peer review process was not carried out in accordance with the Publisher's peer review policy. Author Dandan Wang has not responded to correspondence regarding this retraction. The Publisher has not been able to obtain a current email address for author Zhiqiang Zeng.

The original article can be found online at https://doi.org/10.1007/ s12517-021-07759-z.

Dandan Wang

nice-dandan@163.com

1 College of Physical and Health Education, East China Jiaotong University, Nanchang 330013, Jiangxi, China

2 Student Subjects, Jiangxi Civil Affairs School, Nanchang 330013, Jiangxi, China 